\title{
Uso de uma abordagem baseada em gamificação para a disseminação da cultura de treinamento em uma empresa de tecnologia da informação: $U m$ relato de experiência.
}

\author{
Ana Carolina de Sousa Gonçalves ${ }^{1,3}$, Emanuelle Nogueira Jucá ${ }^{1}$, Francisco Dione \\ de Sousa Amancio ${ }^{1,2}$ \\ ${ }^{1}$ Instituto Atlântico - Rua Chico Lemos, 946, Cidade dos Funcionários - Fortaleza - CE \\ - Brasil \\ ${ }^{2}$ Programa de Pós-Graduação em Informática Aplicada - PPGIA/UNIFOR - \\ Universidade de Fortaleza.
}

${ }^{3}$ Engenharia da Computação - Centro de Tecnologia/UNIFOR - Universidade de Fortaleza.

\{ana_goncalves, emanuelle,dione_amancio\}eatlantico.com.br

Abstract. Technological advances aligned with market competitiveness is making companies search for different ways to increase their productivity through training and qualifying its employees. However, for this, an active participation and motivation of them is necessary. Based on this, this experience report presents an aproach based on structured gamification in the form of a contest to spread the culture of training in the workforce and achieve the goal of the training indicator of an Information Technology company.

Resumo. O avanço tecnológico alinhado à competitividade de mercado vem fazendo com que empresas busquem formas de aumentar sua produtividade por meio da capacitação e qualificação de seus colaboradores. No entanto, para tal é necessário a participação ativa e motivação dos mesmos. Baseado nisto, este relato de experiência apresenta a aplicação de uma abordagem baseada em gamificação estruturada na forma de uma gincana para disseminar a cultura de treinamentos no corpo funcional e atingir a meta do indicador de treinamentos de uma empresa de tecnologia da informação.

\section{Introdução}

A globalização nos últimos anos e o crescimento da utilização da tecnologia de informação na vida cotidiana das pessoas aumentou exponencialmente a complexidade dos softwares e a exigência dos clientes. Dessa forma as organizações passaram a buscar cada vez mais o auxílio de técnicas e metodologias para aumentar a produtividade e assegurar a qualidade dos produtos e serviços oferecidos aos clientes.

Neste contexto, um conjunto de normas e modelos de maturidade como ISO 9001, ISO/IEC 12207, CMMI e MPS.BR são propostos com o objetivo de garantir a qualidade do processo de desenvolvimento, além de reforçar a importância de desenvolver e manter o corpo funcional da organização treinado e alinhado ao mapeamento das competências necessárias para a realização das atividades. 
Baseado nesta realidade, algumas empresas buscam institucionalizar um processo de treinamento e estratégias de monitoramento desse processo, sendo necessárias ações para a disseminação da cultura de capacitação na organização que acredita-se ser fundamental para a entrega de produtos e serviços com maior qualidade. Outro fator de grande influência é a motivação das pessoas envolvidas neste processo. Uma estratégia que vem sendo largamente utilizada nas organizações para promover o engajamento das pessoas é a aplicação de técnicas de gamificação proporcionando um ambiente competitivo de maneira saudável.

Gamificação é definida como o uso de elementos de jogo em contexto fora dos jogos. A idéia principal da gamificação consiste de um mecanismo que premia pessoas em resposta à realização de determinadas atividades que precisam ser incentivadas. A idéia teve início como uma estratégia de marketing para aumentar os compromissos com clientes e, devido à sua eficácia, rapidamente se espalhou para outros domínios, tais como funcionário ou gerenciamento de projetos. [Dubois et al., 2013].

O Atlântico ${ }^{1}$ é uma instituição de pesquisa e desenvolvimento de tecnologia da informação fundada em 2001 que desenvolve projetos de software, hardware e sistemas embargados buscando prover soluções que agreguem valor aos negócios de seus clientes por meio de pessoas motivadas e qualificadas e da melhoria contínua de seus processos. Desde a sua criação, a organização definiu e mantém seus processos com base nos modelos e normas de qualidade existentes no mercado.

Este trabalho relata a experiência na aplicação de uma abordagem motivacional baseada em gamificação, que tem como objetivo estimular a competitividade dos colaboradores a fim de obter a melhoria em alguns objetivos estratégicos que são monitorados por indicadores.

Este trabalho está dividido em 7 seções, incluindo esta Introdução. A seção 2 apresenta os trabalhos relacionados enquanto a seção 3 apresenta uma contextualização da importância da capacitação dos colaboradores. A seção 4 apresenta a problemática do monitoramento do programa de treinamento da organização. A seção 5 apresenta o planejamento, estruturação e aplicação da campanha motivacional baseada em gamificação que utilizamos para tratar as limitações existentes. A seção 6 apresenta os resultados obtidos e a seção 7 discorre sobre a conclusão e as lições aprendidas deste trabalho.

\section{Trabalhos Relacionados}

A gamificação vem sendo aplicada em diversos domínios nos últimos anos, alguns desses domínios de aplicação são: educação, onde elementos do jogo são usados para aumentar a motivação, o envolvimento e desempenho dos alunos [Kapp, 2012], indústria, numa tentativa de melhorar os resultados de empregados no desenvolvimento de suas tarefas diárias e de trabalho [Hugos, 2012] e desenvolvimento de software. Bajdor (2011) faz uso da gamificação para melhorar o gerenciamento de riscos. Fernandes (2012) utiliza uma abordagem para apoiar a colaboração dos envolvidos no processo de elicitação de requisitos. Melo (2014) apresenta uma proposta de aplicação no contexto de gerenciamento de controle de versão. Cavalcante et al.

\footnotetext{
${ }^{1}$ http://www.atlantico.com.br/
} 
(2015) apresenta um relato de experiência da aplicação de uma abordagem baseada em gamificação em uma empresa de desenvolvimento de soluções em tecnologia da informação para a melhoria de processo.

Os trabalhos citados relatam como a gamificação pode ajudar e motivar os colaboradores em diversas áreas. Verificou-se também que inúmeras abordagens e contextos vêm sendo apresentados, no entanto, nenhuma aplicação possui foco em treinamento organizacional.

\section{Contextualização}

A norma NBR ISO 9001:2008, em seu requisito 6.2.2 - Competência, treinamento e conscientização, diz que as organizações devem determinar, para cada função que afete a conformidade com os requisitos do produto, as devidas competências, que se dividem em:

- Conhecimento para a execução das suas tarefas com qualidade;

- Habilidade de executar na prática o que lhe foi estipulado e

- Atitude para realizar seu trabalho com qualidade, eficiência e eficácia.

Além da norma acima citada, Wood Jr et al. (2004) cita que há um aspecto relacionado à competência que precisa ser considerado que é a associação das habilidades, conhecimentos e atitudes com desempenho. Desse modo, pode-se considerar que competência está relacionada com a melhoria do desempenho organizacional e do grupo.

Para tanto foi definida uma estrutura de competências associadas às funções a serem exercidas pelos colaboradores. A organização considera aptos para o desenvolvimento das atividades atribuídas às funções, aqueles colaboradores que forem treinados em todas as competências obrigatórias à sua função. As competências podem ser adquiridas por meio de treinamento presencial ou autoestudo com prova, devendo ser recicladas a cada 18 meses.

Sabe-se que é importante e essencial capacitar e treinar seus funcionários objetivando o aumento da motivação das pessoas, do desempenho delas e da qualidade de seus produtos e serviços. Devido a isto, foi institucionalizada a prática de treinamentos por meio de um processo organizacional, baseado no modelo de maturidade CMMI, associado a um objetivo estratégico de capacitar $70 \%$ dos seus colaboradores com 40 horas de treinamento ao ano.

O processo prevê diversos tipos de treinamentos: competência, técnicos, softskills e aperfeiçoamento (idiomas, pós-graduações e etc.) que podem ser ministrados pelos próprios colaboradores ou por empresas especializadas.

Com o objetivo de monitorar a abrangência do processo de treinamento, foi definido um indicador para medir o percentual de colaboradores que atendem a meta. $\mathrm{O}$ indicador estratégico é coletado a cada três meses, considerando uma proporção da meta anual, de modo que a cada trimestre, os colaboradores devem acumular 10 horas de treinamento totalizando 40 horas anuais. Por meio deste indicador são monitorados todos os treinamentos em que há incentivos da empresa para seu corpo funcional, seja por meio de participação em treinamentos internos, liberação de horas para treinamentos externos, participação em palestras e congressos. 
A partir do Gráfico 1, que ilustra o acompanhamento do indicador ao longo dos anos, verificou-se um grande desvio da meta, concluindo que o monitoramento do processo de treinamento possuía algumas limitações que serão abordadas na próxima seção.

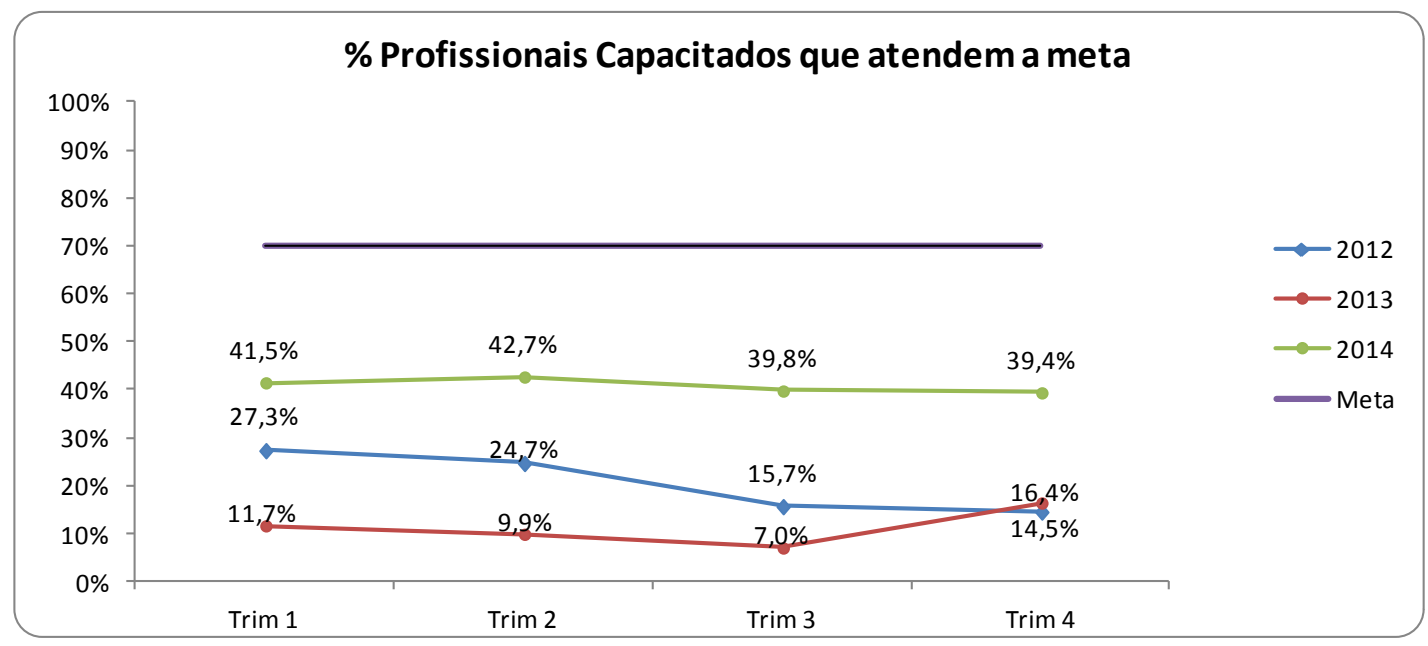

Gráfico 1. Monitoramento trimestral do indicador nos anos de 2012 a 2014

\section{Problemática}

$\mathrm{O}$ indicador que monitora o percentual de profissionais com $40 \mathrm{hs}$ de treinamento no ano foi definido e passou a ser acompanhado no ano de 2012 conforme ilustrado no Gráfico 1. Durante as reuniões de análise dos indicadores estratégicos o corpo gerencial concluiu que os dados coletados não refletiam a realidade da organização, pelas razões listadas a seguir:

- Falta de registro das horas de autoestudo e mentoring que os colaboradores faziam dentro dos projetos. Dessa forma a coleta do indicador contabilizava apenas as horas de treinamentos presenciais;

- As horas de participação em aulas de idiomas custeadas pela organização não estavam sendo contabilizadas;

- Outras capacitações incentivadas pela organização, tais como participação em congressos, pós-graduação e mestrado também não estavam sendo contabilizadas.

Contudo, mesmo diante dos problemas acima citados, o volume de pessoas sendo capacitadas não era suficiente para atender a meta da organização. Por esta razão, foram planejadas algumas ações para tratamento desses problemas conforme exposto na Tabela 1.

Tabela 1. Ações realizadas na organização

\begin{tabular}{|l|l|l|}
\hline \multicolumn{1}{|c|}{ Problemática } & \multicolumn{1}{|c|}{ Ação } & \multicolumn{1}{|c|}{ Detalhamento da Ação } \\
\hline $\begin{array}{l}\text { Falha no registro das } \\
\text { horas de treinamento. }\end{array}$ & $\begin{array}{l}\text { Implementação de } \\
\text { melhorias na plataforma de } \\
\text { aprendizado } \\
\text { conhecimento. }\end{array}$ & $\begin{array}{l}\text { Criação de uma funcionalidade para } \\
\text { registro das ocorrências de } \\
\text { autoestudos de tecnologias, } \\
\text { metodologias e ferramentas realizadas } \\
\text { pelas equipes. }\end{array}$ \\
\hline
\end{tabular}




\begin{tabular}{|c|c|c|}
\hline $\begin{array}{l}\text { Pouco envolvimento } \\
\text { dos colaboradores no } \\
\text { processo } \\
\text { treinamento. }\end{array}$ & $\begin{array}{l}\text { Campanha motivacional } \\
\text { para disseminar a cultura de } \\
\text { treinamento. }\end{array}$ & $\begin{array}{l}\text { - Conscientização dos colaboradores } \\
\text { da importância dos treinamentos para } \\
\text { a empresa; } \\
\text { - Divulgação do monitoramento do } \\
\text { processo de treinamento por meio de } \\
\text { um indicador; } \\
\text { - Divulgação do conceito de } \\
\text { treinamentos incentivados pela } \\
\text { organização e que são contabilizados } \\
\text { no indicador; } \\
\text { - Incentivo para o registro dos } \\
\text { treinamentos realizados; } \\
\text { - Incentivo para a realização de } \\
\text { treinamentos como participantes e } \\
\text { como ministrantes. }\end{array}$ \\
\hline
\end{tabular}

A seção a seguir descreverá com mais detalhes a estruturação da campanha motivacional aplicada.

\section{Campanha Motivacional com Abordagem de Gamificação}

A gamificação vem sendo cada vez mais utilizada nas organizações para incentivar os funcionários de uma empresa, de forma divertida, a alcançar objetivos. Baseado na experiência desta empresa na aplicação descrita e apresentada em Cavalcante et al. (2015), foi comprovado que a gamificação gera resultados positivos e por esta razão, optou-se por utilizar novamente esta estratégia para tratar algumas limitações referentes ao processo de treinamento.

\subsection{Planejamento}

A campanha motivacional teve duração de 8 meses (abril a novembro de 2015) e abordou 3 aspectos que tornaram-se critérios de avaliação conforme descrito abaixo, no entanto, neste trabalho detalharemos apenas os resultados para o processo de treinamento.

- Aderência aos processos organizacionais: Essa aderência é medida por meio do indicador "\% de Não Conformidades (NC)" que é uma relação entre a quantidade de NCs identificadas em uma avaliação de processos e a quantidade de itens avaliados.

- Financeiro: Esse aspecto é medido pelo indicador "Margem de Contribuição (MC)" que considera o que sobrou da receita operacional quando debitados os custos variáveis.

- Capacitação dos colaboradores: Esse aspecto é medido pelo indicador "\% de Profissionais Capacitados" que é uma relação entre a quantidade de colaboradores que proporcionalmente atendem à meta anual de horas de treinamento e a quantidade total de colaboradores da organização. 


\subsection{Caracterização}

Foi feita uma pesquisa com os colaboradores para escolha de uma temática para a campanha. Por se tratar de uma empresa de tecnologia da informação, muitos sugeriram que o tema envolvesse Vídeo Games. A partir da definição do tema deu-se inicio à caracterização da campanha como descrito a seguir:

$\underline{\mathrm{O} j o g o}$

- Jornada Atlante é um jogo composto de 7 fases;

- Os projetos terão 8 meses para finalizar o jogo;

- O desafio é avançar de fase em fase até chegar à fase final;

- As fases do jogo são compostas por obstáculos;

- O desempenho obtido em cada obstáculo vale moedas (os obstáculos representam os indicadores que a organização selecionou para medir durante a campanha);

- Os projetos serão representados pelo jogador "Atlante";

- Os Atlantes podem avançar de fase, se manter ou retroceder de acordo com a quantidade total de moedas acumuladas em cada fase.

Fases do Jogo

- Subsolo (Fase inicial)

- Aquática

- Terrestre

- Montanhosa

- Vulcânica

- Aérea

- Espacial (Fase final)

\subsection{Regras}

Os obstáculos serão avaliados e pontuados conforme as regras apresentadas na Tabela 2.

Tabela 2. Tabela de pontuação dos obstáculos

\begin{tabular}{|l|l|c|}
\hline \multicolumn{1}{|c|}{ Obstáculos } & \multicolumn{1}{|c|}{ Parâmetros para a pontuação } & Pontuação \\
\hline \multirow{2}{*}{\begin{tabular}{l} 
\% de Não $\begin{array}{l}\text { Conformidades } \\
\text { (NCs) }\end{array}$ \\
\cline { 2 - 3 }
\end{tabular}} & $\% \mathrm{NCs}=0 \%$ & 33 moedas \\
\cline { 2 - 3 } & $\% \mathrm{NCs}>0 \% \mathrm{e}<=5,0 \%$ & 30 moedas \\
\hline \multirow{2}{*}{$\begin{array}{l}\% \text { de Profissionais }>5,0 \% \mathrm{e}<=9,0 \% \\
\text { Capacitados }\end{array}$} & $\begin{array}{l}100 \% \text { da equipe está atendendo à meta mensal do indicador } \\
\text { de profissionais capacitados E } \\
100 \% \text { da equipe está treinada em todas as competências } \\
\text { obrigatórias para suas funções }\end{array}$ & 33 moedas \\
\cline { 2 - 3 } $\begin{array}{l}100 \% \text { da equipe está atendendo à meta mensal do indicador } \\
\text { de profissionais capacitados }\end{array}$ & 30 moedas \\
\cline { 2 - 3 } & $\begin{array}{l}\text { Mais de 50\% da equipe está atendendo à meta mensal do } \\
\text { indicador de profissionais capacitados }\end{array}$ & 15 moedas \\
\hline
\end{tabular}




\begin{tabular}{|c|c|c|}
\hline \multirow{3}{*}{$\begin{array}{l}\text { Margem de } \\
\text { Contribuição (MC) }\end{array}$} & $\mathrm{MC}>=$ meta do projeto $+10 \%$ de desvio da meta & 33 moedas \\
\hline & $\begin{array}{l}\text { Meta do projeto }<=\mathrm{MC}<\text { meta do projeto }+10 \% \text { de desvio } \\
\text { da meta }\end{array}$ & 30 moedas \\
\hline & $\begin{array}{l}\text { Meta do projeto }-5 \% \text { desvio da meta }<=\mathrm{MC}>=\text { meta do } \\
\text { projeto }\end{array}$ & 15 moedas \\
\hline
\end{tabular}

As moedas obtidas nos obstáculos serão somadas e dependendo da quantidade de moedas acumuladas os jogadores poderão se mover nas fases do jogo, de acordo com as faixas de valores apresentadas na Tabela 3 .

Tabela 3. Regras para mudança de fase

\begin{tabular}{|l|l|}
\hline \multicolumn{1}{|c|}{ Quantidade de moedas acumuladas no mês } & \multicolumn{1}{c|}{ Movimentação } \\
\hline 0 a 30 moedas & Jogador retrocede de fase \\
\hline 31 a 74 moedas & Jogador permanece na mesma fase \\
\hline Acima de 75 moedas & Jogador avança de fase \\
\hline
\end{tabular}

O projeto com maior quantidade de moedas será o campeão do mês e ganhará um privilégio para usufruir com a equipe.

Ao final do jogo serão premiados todos os projetos representados pelos jogadores Atlantes que chegarem à fase Espacial.

\subsection{Execução}

Esta subseção retrata a execução do jogo Jornada Atlante, o qual contou com a participação de 23 projetos que estiveram ativos durante a campanha, alguns começaram depois, e outras terminaram antes.

Mensalmente os dados referentes aos três obstáculos foram coletados e consolidados de forma a gerar a performance de cada jogador. De acordo com a performance obtida, os jogadores podiam ser bonificados, avançando para a próxima fase, penalizados retrocedendo de fase ou manter-se estáveis na mesma fase. As fases estão listadas na subseção anterior e demonstradas na Figura 1, que representa um esboço do painel de acompanhamento, a partir do qual é possível observar a disposição dos projetos participantes, representados pelos jogadores Atlantes nas diversas fases do jogo.

Para que todos os projetos pudessem acompanhar o seu resultado mensal, faziase uma divulgação dos resultados parciais, em um painel disponibilizado no pátio da empresa que continha a representação de um jogador para cada projeto. Na divulgação a alta direção parabenizava todos os projetos que avançavam de fase, e premiava o ganhador do mês. 


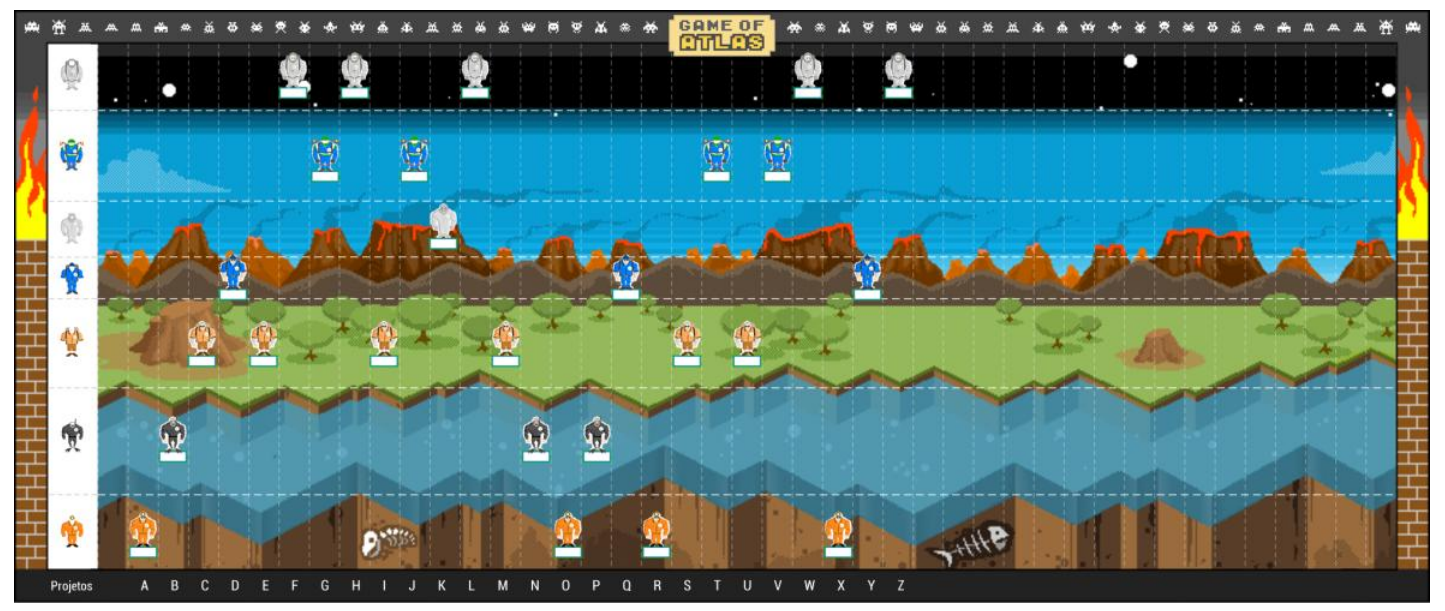

Figura 1. Esboço do painel de acompanhamento

Ao final da campanha foram premiados 90 colaboradores que compunham as equipes dos 12 projetos que ganharam o jogo ao chegar à fase espacial.

\section{Resultados}

Nesta seção serão apresentados os resultados da aplicação da campanha motivacional para tratar a problemática descrita na seção 4 e os reflexos dessa campanha no indicador de $\%$ de profissionais capacitados.

O Gráfico 2 ilustra a média de pontos acumulados, no critério de avaliação relativo às horas de treinamento, pelos projetos mês a mês durante o período de realização do jogo. A partir do gráfico podemos observar que no primeiro mês do jogo os projetos acumularam em média 13,31 pontos, enquanto que ao final do jogo a média passou para 24,18 , representando um aumento de $81,7 \%$.

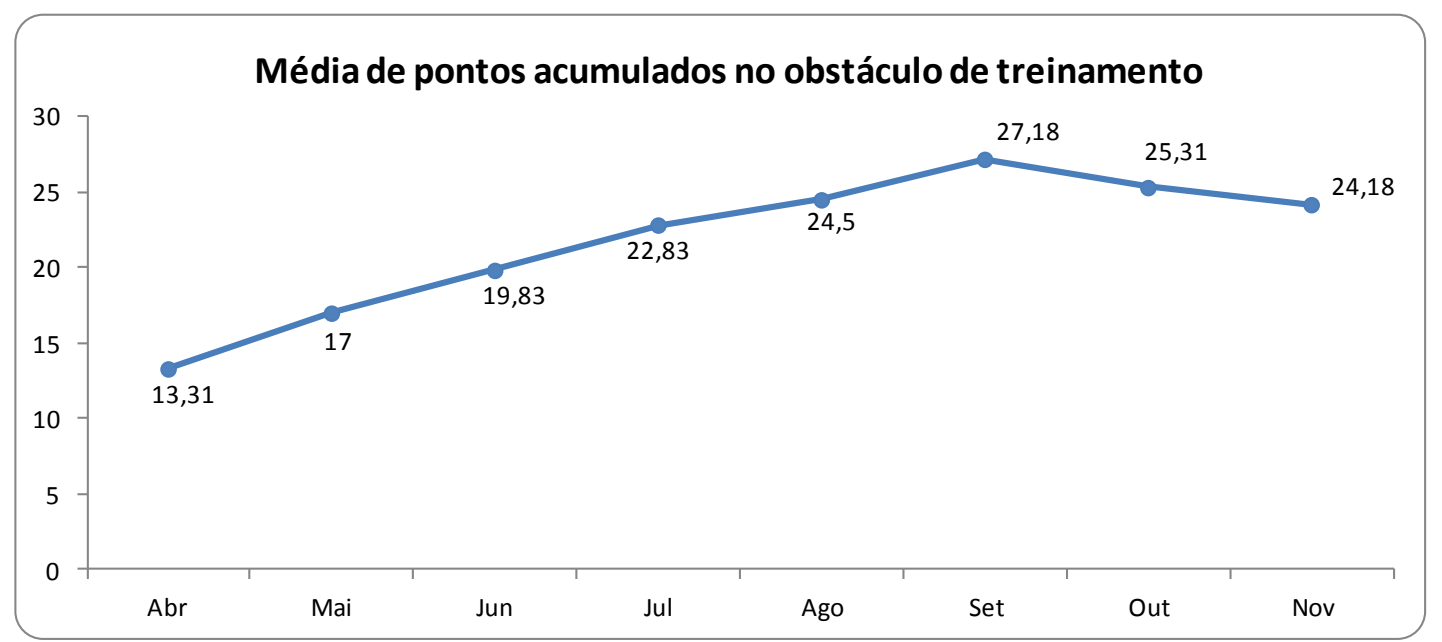

Gráfico 2. Acompanhamento da média de pontos acumulados no critério de avaliação relativo às horas de treinamento

A partir dos dados coletados para a consolidação do jogo, verificou-se que no primeiro mês apenas 3 projetos estavam com $100 \%$ da equipe atendendo a meta. Em contrapartida, no último mês do jogo 8 projetos estavam com $100 \%$ da equipe atendendo a meta. Nesse cenário a melhoria foi de 166,7\%. 
A partir do Gráfico 3 pode-se observar a evolução do percentual de participantes do jogo que atendem à meta de horas de treinamento. Percebe-se um aumento significativo ao longo dos meses do jogo.

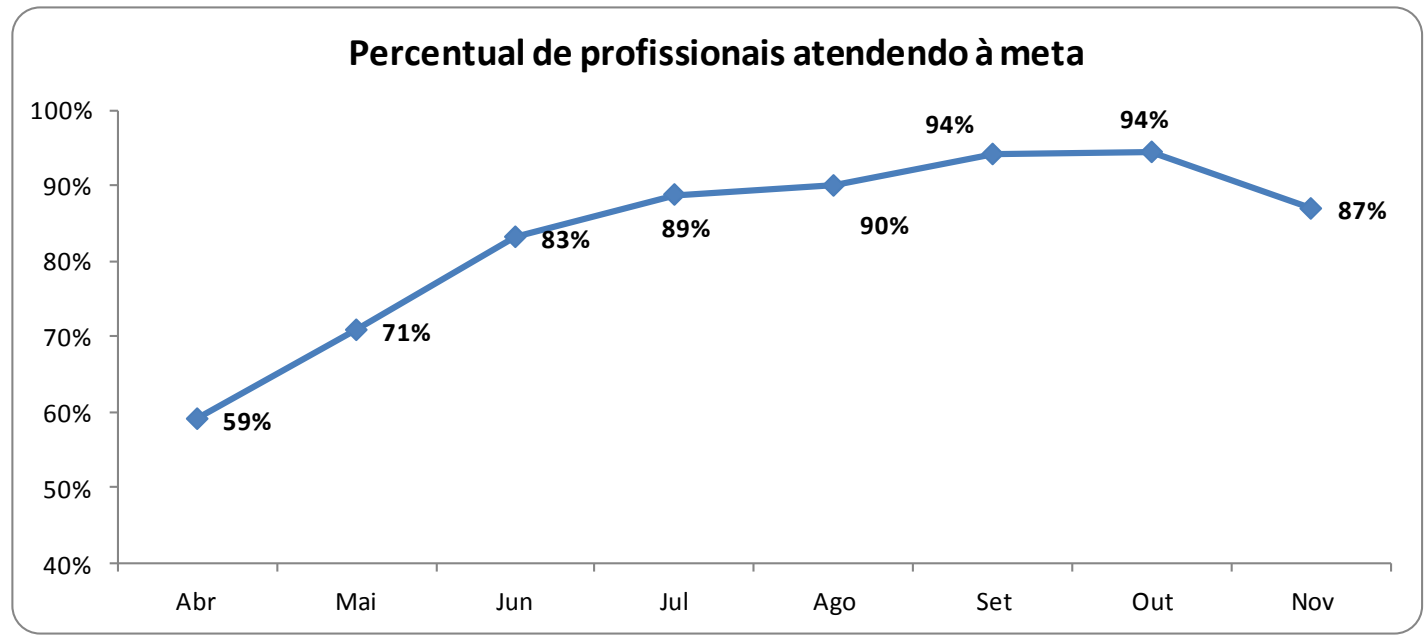

Gráfico 3. Demonstrativo mensal do atendimento à meta dentre os colaboradores participantes do jogo

O Gráfico 4 ilustra a coleta mensal do indicador \% de Profissionais Capacitados no ano de 2015, considerando todos os colaboradores da organização. Verifica-se uma evolução no decorrer dos meses, no entanto percebe-se que no início do jogo (mês de abril) houve uma melhora significativa em relação aos meses anteriores.

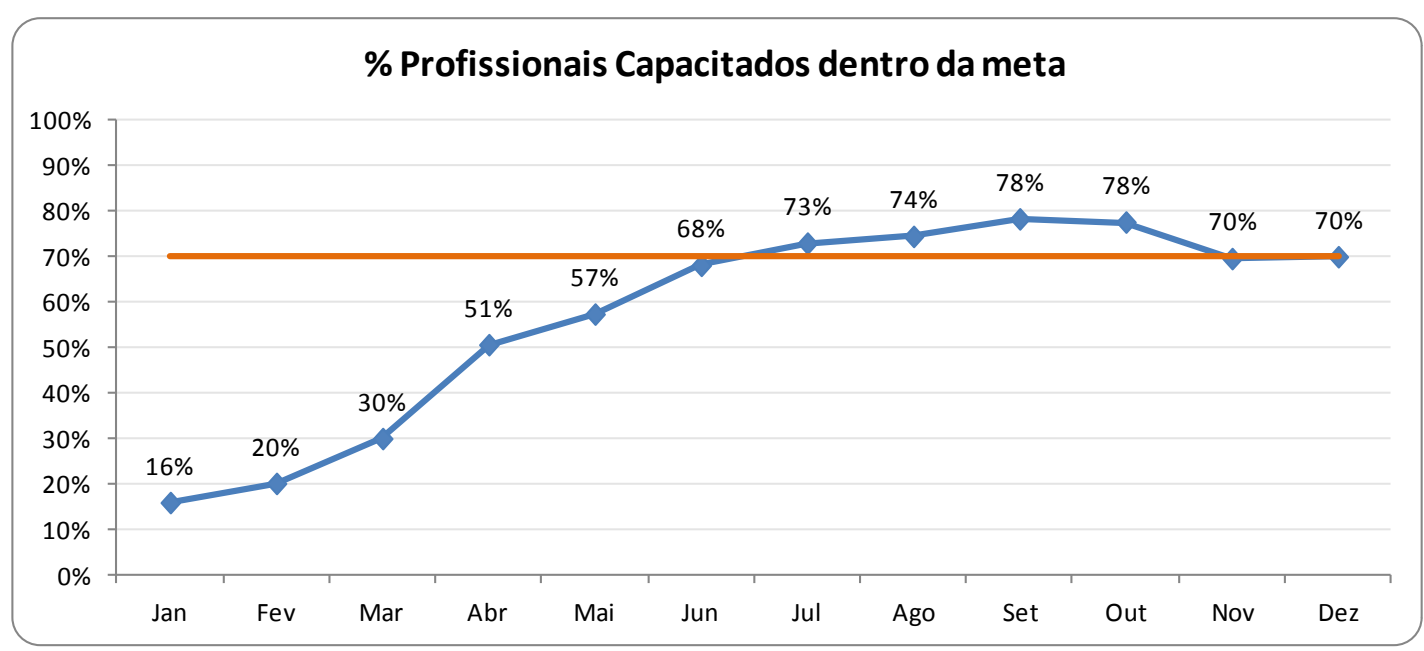

Gráfico 4. Coleta mensal do indicador \% de Profissionais Capacitados em 2015

Os dados dos Gráficos 3 e 4 diferem entre si porque o Gráfico 3 ilustra apenas os colaboradores participantes do jogo, enquanto que o Gráfico 4 ilustra o cenário de toda a empresa, que incluem pessoas das áreas de apoio que não participaram da campanha, tais como as áreas Administrativa, Comercial, Suporte TI, Qualidade, Inovação e Comunicação. 


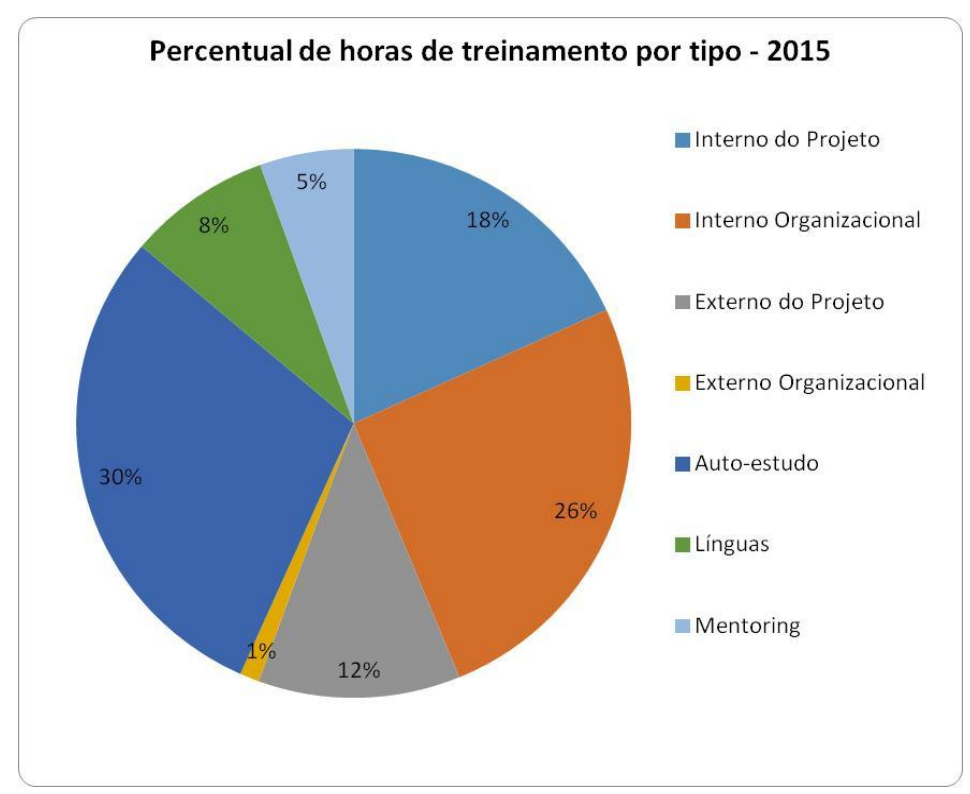

\section{Gráfico 5. Classificação dos treinamentos realizados pelos colaboradores}

O Gráfico 5 ilustra que $48 \%$ das horas de treinamento está concentrada em horas de autoestudo e mentoring, que são modalidades de treinamento que não estavam sendo medidas, reforçando a percepção de que ao longo dos anos os colaboradores eram treinados, mas o processo de registro e monitoramento dos treinamentos não era eficaz.

\section{Conclusão}

Este trabalho teve como objetivo apresentar a aplicação dos conceitos de gamificação em uma campanha motivacional para aumentar o engajamento do corpo funcional relativo ao Programa de Treinamento da organização, que é monitorado por meio do indicador \% de Profissionais Capacitados.

Após o encerramento da campanha e análise do status final do indicador, concluiu-se que:

- A gamificação proporciona um ambiente competitivo saudável que motiva o atendimento de objetivos;

- O sentimento de time foi fortalecido, gerando uma maior integração dos membros de cada equipe, pois não eram avaliados resultados individuais e sim os resultados do time como um todo;

- Houve um aumento na participação dos colaboradores nos treinamentos;

- Com base nos dados percebeu-se uma melhora no reconhecimento por parte dos colaboradores da importância dos treinamentos para a organização;

- Os colaboradores passaram a conhecer o indicador que monitora as horas de treinamento do corpo funcional da empresa;

- Os colaboradores entenderam que mentoring e autoestudo também são treinamentos considerados válidos para a organização, visto que são horas de treinamento realizadas dentro da jornada de trabalho;

- As horas realizadas com treinamentos do tipo cursos de idiomas, mentoring e autoestudo passaram a ser registradas e contabilizadas; 
- Havia falhas no processo de registro e monitoramento dos treinamentos. Estas foram identificadas e tratadas por meio de melhorias na plataforma de aprendizado e conhecimento, de modo a proporcionar maior facilidade aos gestores no registro dos treinamentos;

- Um maior apoio da alta direção é um fator crítico de sucesso para o programa de treinamento.

Abaixo estão listadas as lições aprendidas identificadas:

- Empresas de tecnologia da informação, como é o caso do Atlântico, tem grande parte do seu corpo funcional composto por pessoas jovens que estão em busca constante por novos desafios, e a aplicação de técnicas de jogos é um fator de motivação em busca de resultados;

- O processo organizacional precisa estar em constante avaliação e melhoria contínua. O processo de treinamento existente estava bem consolidado, apesar disso o próprio processo, bem como as ferramentas utilizadas para seu gerenciamento, pode ser constantemente evoluído;

- O processo de conscientização dos colaboradores deve ser constante. Em alguns casos a organização acredita que o corpo funcional está ciente das normas e diretrizes, mas isso nem sempre ocorre, sendo necessário um trabalho contínuo de divulgação e conscientização;

- As técnicas de gamificação podem ser aplicadas em qualquer área ou empresa, sendo necessária, para tanto, uma análise para identificar pontos de melhoria que possam ser afetados pela motivação dos colaboradores e identificar uma caracterização que mobilize as pessoas.

A empresa vem aplicando os princípios da gamificação em diversas atividades contribuindo para a disseminação da cultura dos jogos e maior aceitação da mesma. Apesar disso, ao longo da aplicação da campanha percebeu-se alguma resistência por parte dos colaboradores relacionada ao comparecimento às cerimônias de divulgação dos resultados, dado que algumas pessoas julgavam demoradas. Isso foi tratado com a reformulação da dinâmica de divulgação.

Por fim, concluiu-se que as técnicas de gamificação mostraram-se eficientes em sua aplicação no contexto deste trabalho, além de promover a melhoria do processo, da integração, senso de trabalho em equipe e motivação entre os colaboradores. Identificou-se também, que o apoio da alta direção foi essencial para o sucesso da campanha, resultando em maior comprometimento dos participantes. Concluiu-se ainda que outras empresas podem aplicar a estratégia utilizada neste relato de experiência.

\section{Referências}

Associação Brasileira de Normas Técnicas (2008). "NBR ISO 9001 - Sistema de Gestão da Qualidade - Requisitos". ABNT, Rio de Janeiro, Novembro de 2008.

Bajdor, Paula; Dragolea, Larisa (2011). "The gamification as a tool to improve risk management in the enterprise". In. Annales Universitatis Apulensis: Series Oeconomica, v. 13, n. 2, p. 574, 2011.

Bitencourt, Ricardo Barbosa. (2014) "Experiência de gamificação do ensino na Licenciatura em Computação no Sertão Pernambucano". In. XIII Simpósio Brasileiro de Games e Entretenimento Digital, Porto Alegre, Brasil. 
Cavalcante, N., Amancio, F., Juca, E. e Rodrigues, M. (2015). "Uso de Gamificação como Auxílio para Melhoria de Processos: Relato de Experiência", In: XIV Simpósio Brasileiro de Qualidade de Software, Manaus, Brasil.

De melo, Alexandre Altair et al. (2014) "Version Control System Gamification: A proposal to encourage the engagement of developers to collaborate in software projects". In: International Conference on Social Computing and Social Media. Springer International Publishing, 2014. p. 550-558.

Dubois, D. J.; Tamburrelli, G. (2013) "Understanding Gamification Mechanisms for Software Development." In: Proceedings of the 2013 9th Joint Meeting on Foundations of Software Engineering. ESEC/FSE 2013. New York, NY, USA

Fernandes, João et al. (2012) "iThink: a game-based approach towards improving collaboration and participation in requirement elicitation." In. Procedia Computer Science, v. 15, p. 66-77, 2012.

Fuggetta, A., (2000), "Software Process: A Roadmap". In: Proceedings of the Conference on The Future of Software Engineering. ICSE '00. New York, NY, USA: ACM, p. 25-34.

International Organization For Standardization/ International Electrotechnical Comission (2008). "ISO/IEC 12207 Systems and software engineering - Software life cycle processes", In. Geneve.

Neeli, Basanth Kumar. (2012) "A method to engage employees using gamification in BPO industry”; In. Services in Emerging Markets (ICSEM), Third International Conference On.

SEI (2010). "CMMI for Development, Version 1.3". Technical Report CMU/SEI-2010TR-033. Software Engineering Institute - Carnegie Mellon University.

Softex (2016). "MPS.BR - Melhoria de Processo do Software Brasileiro, Guia Geral MPS de Gestão de Pessoas", SOFTEX, Agosto.

Wood Jr., T.; Picarelli Filho, V. (2004). "Remuneração e carreira por habilidades e por competências: preparando a organização para a era das empresas de conhecimento intensivo". 3. ed. São Paulo: Atlas. 